\title{
PARAÍSO DAS ÁGUAS... E O LIXO?
}

\section{Paola Bueno Quirino 1}

\section{Maria Bento da Rocha ${ }^{2}$}

\section{Luana Mendes Monteiro Moura ${ }^{3}$}

Resumo: Paraíso das Águas é o mais novo Município situado no nordeste do Estado de Mato Grosso do Sul, efetivamente nascido em $1^{\circ}$ de janeiro desse ano. É da herança como Distrito que surgiu o interesse em contribuir com reflexões a respeito do desenvolvimento local. O principal foco de contribuição está relacionado no fornecimento de subsídios na busca do local ideal para instalação de atividades inerentes à produção e destino do lixo urbano. Durante esse ano todos os levantamentos de dados permitiram extrair e analisar informações de uma realidade que tem sido comum na maioria dos municípios de pequeno porte em Mato Grosso do Sul, qual seja a busca por ações prioritárias que minimizem o Maximo o constante desconforto gerado pela geração de lixo. Os resultados apresentados, oriundos da visita ao local, publicações, caracterização e entendimento da estrutura física do território e o significado das prioridades estabelecidas pelo município com relação aos resíduos sólidos, permitiram contribuir com indicadores de áreas que possam vir a abrigar o conjunto de atividades que levam ao reaproveitamento dos resíduos sólidos.

Palavras-chave: Dilemas urbanos. Paraíso das Águas. Resíduos Sólidos.

\footnotetext{
1 Graduada em Geografia, UFMS/CPAQ. pa_facul@hotmail.com

2 Graduanda em Geografia, UFMS/CPAQ. Maria.benta_ufms@hotmail.com

${ }^{3}$ Graduanda em Geografia, UFMS/CPAQ. luana23.moura@hotmail.com
} 


\section{INTRODUÇÃO}

Criado pela lei 2.679 de 29 de setembro de 2003, o Município de Paraíso das Águas localiza-se na porção nordeste do estado de Mato Grosso do Sul. Tem como municípios limítrofes: Camapuã, Água Clara, Chapadão do Sul, Costa Rica. Sua área territorial é de $4.869,71 \mathrm{Km}^{2}$.

O Município foi instalado administrativamente em 1ํㅡ de Janeiro de 2013, portanto alguns dados se referem à época de sua condição como Distrito de Costa Rica, destacando-se nesse período um intervalo de exatamente uma década para que sua independência se tornasse concreta. Esse intervalo de tempo foi motivado por questionamento judicial impetrado pela Prefeitura de Água Clara cujo impasse durou até dezembro de 2009. O Supremo Tribunal Federal deu ganho de causa validando o decreto estadual que dava autonomia a Paraíso das Águas. Além disso, a Assembléia Legislativa de Mato Grosso do Sul decidiu que as eleições para Prefeito e Vereadores acontecessem somente em 2012. Portanto o Município continuou como distrito de Costa Rica até 31 de Dezembro 2012 e, atualmente, pertence judicialmente à comarca de Costa Rica.

A população residente, segundo o censo demográfico do IBGE em 2010 apresentava-se num quantitativo de 2.010 pessoas, estando $84 \%$ residindo na sede do então Distrito. No final de 2012, segundo estimativas, o quantitativo teria aumentado em mais de $110 \%$. Ainda, a população residente por grupos de Idade, segundo o mesmo censo, nas faixas de 0 a 39 anos, representava $67 \%$ do total de moradores, indicando tratar-se de uma população fortalecida nas categorias jovem a meia idade.

Em 2012, ano da primeira eleição no município, para prefeito e vereadores, com base na estimativa populacional do mesmo ano, havia 3.430 eleitores, ou aproximadamente $70 \%$ daquela população, estando à maioria deles na faixa etária dos 18 aos 44 anos, segundo o Tribunal Regional Eleitoral do Estado de Mato Grosso do Sul (2013).

2 ORGANIZAÇÃO DO BANCO DE DADOS 
A equipe organizadora desse trabalho esteve visitando o Município em fevereiro de 2013 para coletar subsídios relacionados principalmente com as questões geográficas que pudesse originar argumentações que justificassem a implantação desse mais novo município de Mato Grosso do Sul, o de número 79.

As informações obtidas através de conversas informais com moradores de Paraíso das Águas revelaram alguns entraves que no inicio do ano de 2013 dificultavam o desenvolvimento ideal esperado pela população. Dessas conversas houve manifestações tais como:

- Na área da saúde havia carências tanto de estrutura física (Hospital e Unidade de Pronto Atendimento - UPA) como de profissionais de atendimento médico e administrativo;

- Com relação à disponibilização de atividade de lazer os moradores também disseram da deficiência em diversas modalidades tais como: esportivas e principalmente aquáticas;

- Na educação reclamavam da falta de creches, prédios escolares e oportunidades de qualificação com ofertas de cursos profissionalizantes;

- No setor de moradias a questão inflacionaria inviabilizava a aquisição de terrenos para a classe menos favorecida, alem do que o Município também elevou o custo do imposto sobre a propriedade urbana. Nesse assunto parece haver faltado dialogo da administração Municipal com os moradores, já que o legislativo Municipal parecia ainda não haver assumido plenamente suas funções.

Ainda nas questões de segurança pode se dizer que toda a infraestrutura adequada deixava muito a desejar, pois a relação população/proteção policial é muito contrastante. Outros setores também foram lembrados pelos moradores como a questão das comunicações telefônicas, transporte municipal e outros serviços incluindo-se um deles que consideram primordial, atividades industriais para geração de empregos. Também reclamaram que deve ser considerada a da qualidade dos serviços da iluminação pública, também com algumas deficiências.

Os dados iniciais coletados permitiram constar que a área urbana é ricamente beneficiada com pavimentação asfaltica e infraestrutura de água tratada e energia elétrica, deixando de ser coerente nas questões de saneamento básico, principalmente por que este último assunto contrasta ao nome dado à cidade sede "Paraíso". 
A Cidade de Paraíso soma-se àquelas cidades de arranjo da malha urbana encravadas em trecho de encosta, limitada pela BR 060, em direção ao fundo do vale dos rios Paraíso/Mimoso, formadores do lago da usina hidrelétrica de Mimoso. O sistema de arruamento apresenta, portanto, ruas que são perpendiculares a declividade da encosta principal, sendo as quadras definidas por ruas que acompanham o mergulho das encostas, sem, no entanto, obedecer a uma regularidade no traçado geométrico das malhas. Para melhor compreender o quadro urbano, foram levantadas as coordenadas geográficas baseados em extremidades de pontos que simbolizavam limites do perímetro urbano. Os valores obtidos constam no quadro a seguir:

\begin{tabular}{|c|l|l|c|}
\hline Pontos & \multicolumn{1}{|c|}{ Latitude } & \multicolumn{1}{|c|}{ Longitude } & Altitude \\
& & & \\
\hline $1^{\circ}$ & $\left.19^{\circ} 01^{\prime} 02^{\prime \prime}\right)$ & $53^{\circ} 00^{\prime} 892^{\prime \prime}$ & 1.959 \\
\hline $2^{\circ}$ & $1^{\circ} 01^{\prime} 305^{\prime \prime}$ & $53^{\circ} 01^{\prime} 095^{\prime \prime}$ & 2.053 \\
\hline $3^{\circ}$ & $1^{\circ} 01^{\prime} 844^{\prime \prime}$ & $53^{\circ} 00^{\prime} 934^{\prime \prime}$ & 2.084 \\
\hline $4^{\circ}$ & $1^{\circ} 01^{\prime} 305^{\prime \prime}$ & $53^{\circ} 00^{\prime} 235^{\prime \prime}$ & 1.864 \\
\hline
\end{tabular}

Quadro 01 Paraíso das Águas - Pontos do Perímetro (ocupados por habitações urbanas)

Fonte: Quirino, et al (Fevereiro de 2013) GPS Garmin (UFMS).

A equipe manteve contato com pessoas residentes em Paraíso, conversando com elas informalmente a respeito da nova situação, de perspectivas futuras, dada a passagem do estado de Distrito para Município. Dentre as conversas soube-se da existência da área utilizada como lixão, na bacia hidrográfica do córrego sem denominação, afluente do rio Paraíso, na Bacia Hidrográfica do rio Sucuriú. Em visita ao local, a primeira impressão que se teve foi a de que havia muito lixo depositado para uma quantidade muito pequena de habitantes (1.709 habitantes em 2010 - censo IBGE).

Há aproximadamente duas décadas os estudos científicos, diante dos problemas que a deposição do lixo a céu aberto vinha apresentando, começaram a divulgar indicadores para a escolha do local ideal para a disposição do lixo.

De lá para cá o que se seguiu foram buscas incessantes na tentativa de solucionar os problemas ambientais decorrentes da produção do lixo. Surgiram então às indústrias de transformação do lixo reciclado, o aumento do quantitativo de empresas e pessoa física, intermediarias entre os que produziam lixo e os que o transformavam em produtos 
reutilizáveis. O que a equipe viu no lixão de Paraíso representava dominantemente a disposição do lixo a céu aberto, com pouca representatividade no trabalho de coleta seletiva in loco, que pode ser constatado nas figuras 01,02 e 03.

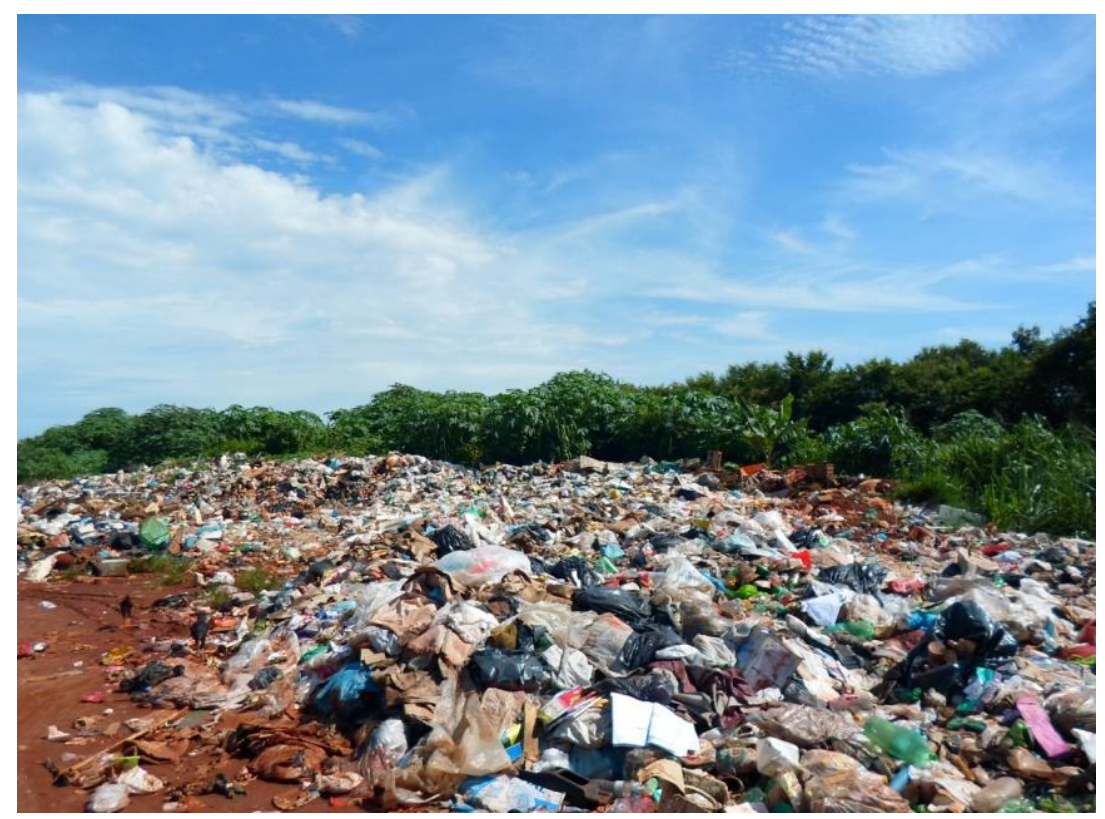

Figura 01 Paraíso das Águas: Lixão a céu aberto. Fonte: Quirino, 2013.

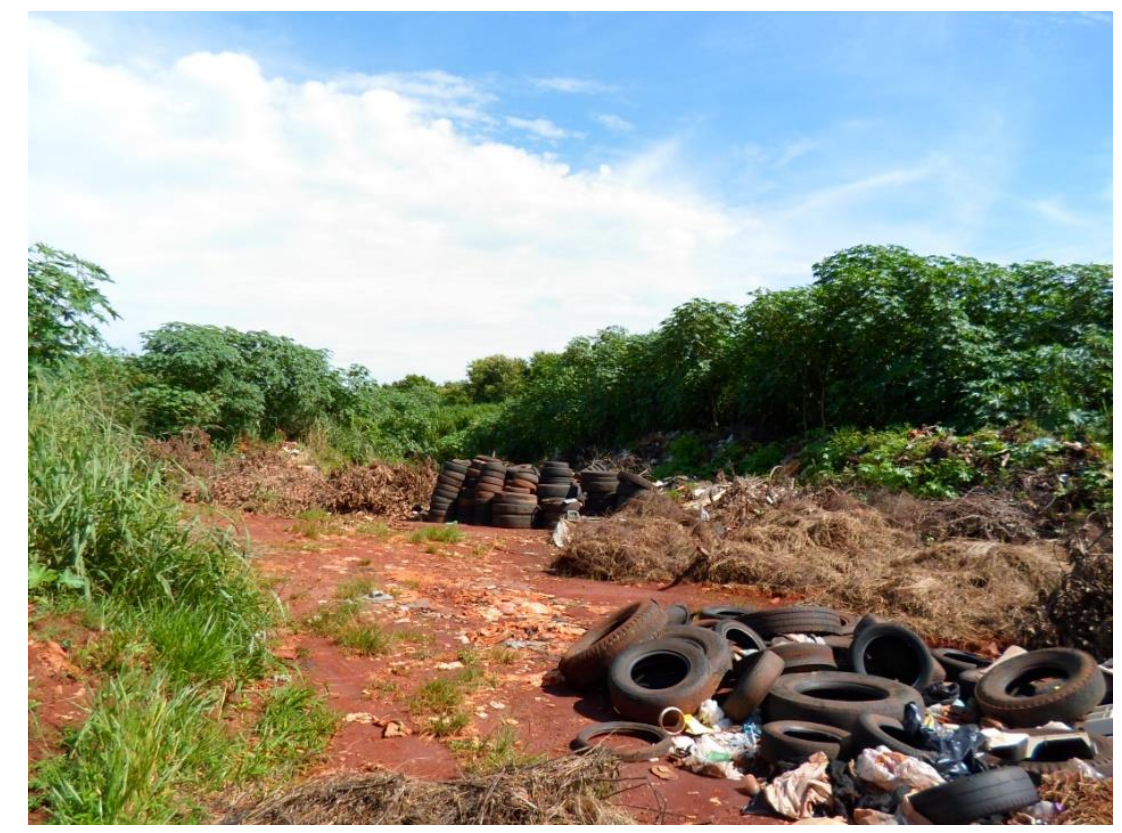

Figura 02 Paraíso das Águas: matéria orgânica e pneus (ambos reaproveitáveis)

Fonte: Quirino, 2013. 


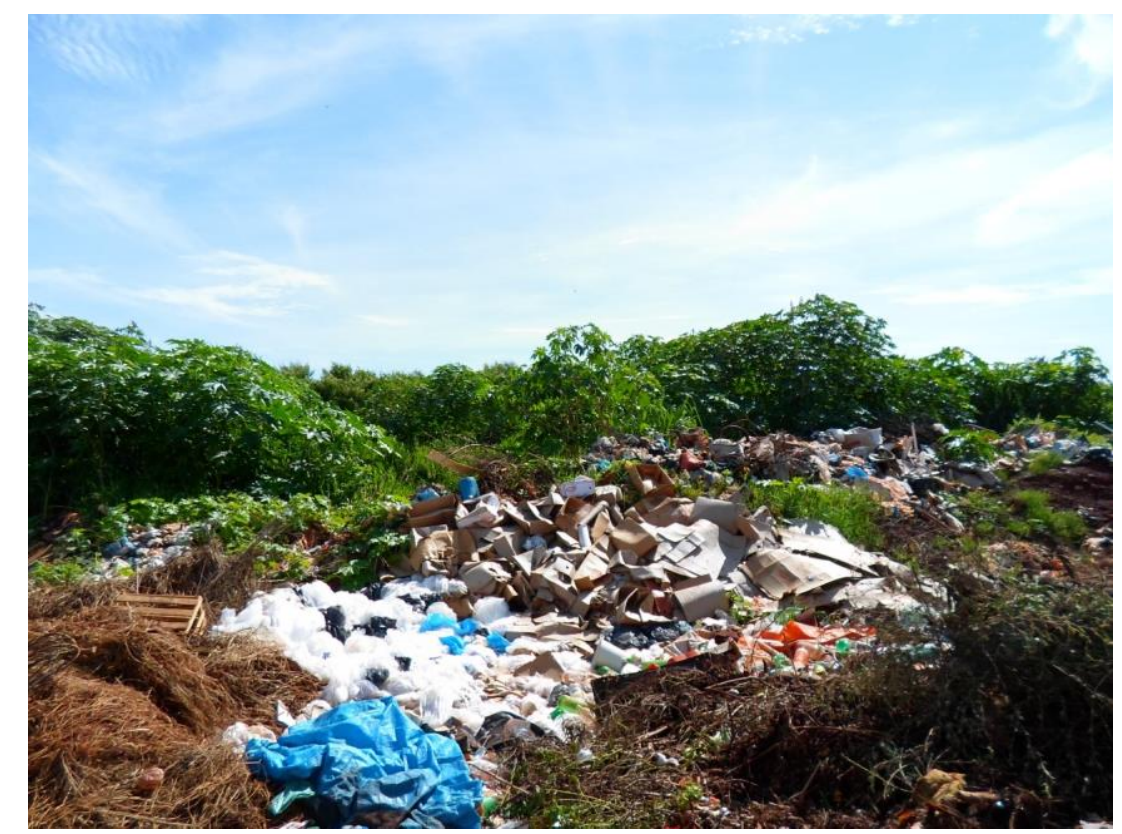

Figura 03 Paraíso das Águas: Lixão onde o processo de disposição dificulta muito qualquer tentativa de busca de material reciclável.

Fonte: Quirino, 2013.

Recentemente, através da "Home Page" da Prefeitura Municipal a equipe tomou conhecimento da chamada para a realização da 1a Conferencia Municipal do Meio Ambiente de Paraíso das Águas, programada para ser realizada no dia 24 de Julho de 2013. Naquela oportunidade chamou a atenção o fato de que o lixo produzido em Paraíso estava sendo levado para um aterro sanitário localizado no Município de Chapadão do Sul, distante aproximadamente 50 (cinqüenta) quilômetros, em direção à divisa com o Estado de Goiás.

Realizada, a Conferência apresentou os seguintes resultados apontados como ações prioritárias:

\subsection{Eixo 1 - Produção e Consumo Sustentáveis}

\begin{tabular}{|c|l|}
\hline Prioridades & \multicolumn{1}{c|}{ Ação } \\
\hline 1 & $\begin{array}{l}\text { Criação de compoteira municipal proveniente de poda } \\
\text { paisagística e jardinagem }\end{array}$ \\
\hline 2 & Criação de aterro sanitário municipal ou em consórcio \\
\hline 3 & Criação de uma Unidade de Processamento de Lixo - UPL \\
\hline 4 & $\begin{array}{l}\text { Criação de lagoas de decantação para fossas sépticas e } \\
\text { criação de uma rede de Esgotamento sanitário e Estação de } \\
\text { Tratamento de Esgoto - ETE }\end{array}$ \\
\hline
\end{tabular}




\section{5}

Utilização de, no mínimo, 30\% de materiais para as obras públicas ou privadas oriundas de empresas com certificação ambiental.

Quadro 02: Produção e consumos sustentáveis.

Fonte: $1^{\circ}$ Conferência Municipal do Meio Ambiente de Paraíso das Águas, 2013.

Dentre as prioridades apontadas no eixo 1, nos pareceu de maior urgência a criação de uma unidade de processamento de lixo, uma vez que o local atual de "lixão" é inadequado para deposição do lixo, por estar em área próxima a curso d’água, e residências.

\subsection{Eixo 2 - Redução Dos Impactos Ambientais}

\begin{tabular}{|c|l|}
\hline Prioridades & \multicolumn{1}{|c|}{ Ação } \\
\hline 1 & $\begin{array}{l}\text { Desenvolver campanhas de conscientização da população } \\
\text { sobre a destinação adequada dos resíduos sólidos. }\end{array}$ \\
\hline 2 & $\begin{array}{l}\text { Criação de ecopontos multifuncionais. } \\
\text { Desenvolver projeto de coleta seletiva com dias semanais } \\
\text { específicos para coleta de secos e molhados. }\end{array}$ \\
\hline 3 & $\begin{array}{l}\text { Instalar coletores recicláveis em instituições e logradouros } \\
\text { públicos. }\end{array}$ \\
\hline 5 & $\begin{array}{l}\text { Criar hortas escolares e, juntamente com as mesmas, } \\
\text { compoteiras que utilizarão os resíduos orgânicos das cozinhas } \\
\text { das Unidades Escolares. Os legumes e verduras produzidos } \\
\text { enriquecerão a merenda escolar. }\end{array}$ \\
\hline
\end{tabular}

Quadro 03: Redução dos Impactos Ambientais.

Fonte: $1^{\circ}$ Conferência Municipal do Meio Ambiente de Paraíso das Águas, 2013.

Desenvolver campanhas de conscientização da população sobre a destinação adequada dos resíduos sólidos pareceu ser a prioridade que melhor combina com aquela apontada no eixo 1, pois a população precisa tomar conhecimento da destinação final dos resíduos de maneira correta com intuito de minimizar o impacto ambiental e diminuir o acumulo desses materiais em áreas preservadas, contribuindo para a saúde da população. 


\subsection{Eixo 3 - Geração De trabalho, Emprego e Renda}

\begin{tabular}{|c|l|}
\hline Prioridades & \multicolumn{1}{c|}{ Ação } \\
\hline 1 & $\begin{array}{l}\text { Promoção de feiras, para revendas de produtos feitos a partir de } \\
\text { resíduos sólidos ou reutilizáveis. }\end{array}$ \\
\hline 2 & $\begin{array}{l}\text { Criar cooperativas de catadores, com grupo especializado em } \\
\text { educação interativa, que atinja os lares e fiscalize e oriente a } \\
\text { separação dos resíduos nos domicílios. }\end{array}$ \\
\hline 3 & $\begin{array}{l}\text { Capacitação dos catadores e outros profissionais nas áreas de } \\
\text { manejo, manufaturação e manipulação correta e segurança no } \\
\text { trabalho. }\end{array}$ \\
\hline 4 & $\begin{array}{l}\text { Estimulação governamental através de linhas de crédito estatais } \\
\text { e incentivo fiscal para criação de cooperativas com gestão } \\
\text { compartilhada de catadores e outros profissionais envolvidos no } \\
\text { manejo de resíduos sólidos. }\end{array}$ \\
\hline 5 & $\begin{array}{l}\text { Criação de oficinas permanentes de artesanato que utilizem } \\
\text { como matéria prima resíduos sólidos e recicláveis e reutilizáveis. }\end{array}$ \\
\hline
\end{tabular}

Quadro 04: Geração de Trabalho, Emprego e Renda.

Fonte: $1^{\circ}$ Conferência Municipal do Meio Ambiente de Paraíso das Águas, 2013.

Geração de emprego e renda. O que pode trazer um bom resultado beneficiando assim a população, o Município e a ordem de prioridade - Criar cooperativas de catadores de resíduos, com grupo especializado em educação interativa, que atinja a população, fiscalizando e orientando de como fazer a separação dos lixos nas residências, contudo os catadores têm grande importância por retirarem os resíduos, os quais constituiriam uma fonte de renda, desde que os serviços dos catadores cooperados servissem de estímulo aos moradores, para manutenção do processo.

\subsection{Eixo 4 - Educação Ambiental}

\begin{tabular}{|c|c|}
\hline $\begin{array}{l}\text { Ordem de } \\
\text { Prioridade }\end{array}$ & Ação \\
\hline 1 & Criação de lei municipal para reeducação dos comerciantes \\
\hline
\end{tabular}




\begin{tabular}{|c|l|}
\hline & quanto ao uso de embalagens ecologicamente corretas. \\
\hline 2 & $\begin{array}{l}\text { Realização de campanhas de conscientização da população } \\
\text { para coleta específica de galhos e folhas pelo município. }\end{array}$ \\
\hline 3 & $\begin{array}{l}\text { Adição de disciplina obrigatória para ensino fundamental e } \\
\text { médio relacionada à disciplina Educação Ambiental. }\end{array}$ \\
\hline
\end{tabular}

Quadro 05: Educação Ambiental.

Fonte: $1^{\circ}$ Conferência Municipal do Meio Ambiente de Paraíso das Águas, 2013.

Ainda, mantendo coerência com as prioridades escolhidas, a Adição da disciplina obrigatória para ensino fundamental e médio relacionada à disciplina Educação Ambiental, além do ensinar, ajuda a criar novos debates, valorizar o meio ambiente, conservando e preservando, criando assim perspectiva futura, com qualidade de vida bem como o respeito e comprometimento do ambiente em que vive.

\section{DIAGNÓSTICOS E RESULTADOS}

\subsection{Adequação Espacial}

De acordo com o mapa geológico do Estado de Mato Grosso do Sul, editado em 2006 a área do município de Paraíso das Águas apresenta substrato rochoso representado por rochas do grupo Caiuá e São Bento.

No grupo Caiuá aparecem arenitos quartzosos subarcoseano fino a médio. Ambiente continental desértico, dunas eólicas, interdunas e lagos efêmeros.

Dentro do mesmo grupo aparecem os arenitos quartzosos da formação Santo Anastácio, de textura fina a muito fino de pouca matriz silico-argilosa e intercalação de argilito. Os sedimentos foram depositados em ambiente continental desértico e planícies de borda de maré de areia.

No grupo São Bento aparecem rochas magmáticas da formação Serra Geral, representados por basaltos andesitos de filiação toleiticas intercalados por camadas de arenitos e lito-arenitos.

O retrato geológico tem um significado especial no tocante á questão do lixo devido aos problemas dele gerados. É importante considerar este elemento quando na aplicação das políticas de planejamento voltadas ao meio ambiente. Os caminhos na busca do local ideal para a instalação de quaisquer atividades inerentes ao lixo incluem com certeza um 
diagnóstico mais preciso da representação geológica do território. Como exemplo local, cita-se o canal fluvial do rio Sucuriú com todo percurso do seu leito sustentado por basaltos.

Examinando a disposição da rede de drenagem distribuída nas cartas planialtimétricas: Rio São Domingos; Ribeirão Brejão; Costa Rica; Cabeceira do Aporé; Alto Sucuriú; Paraíso e Ribeirão Boa Vista, as primeiras impressões revelam, com base na equidistância das curvas de nível, principalmente consideradas as crenulações indicadoras de fundos de vales, uma diversidade de adensamento de canais fluviais.

Seguindo pelo canal do rio Verde nas cartas rio São Domingos e ribeirão Brejão, em território do Município de Paraíso, confirma-se que as encostas ganham aumentos progressivos na altitude desde os 450 aos 750 metros, sendo este ultimo valor representando poucos pontos cotados.

Nesse espaço a amplitude altimétrica em torno dos 300 metros numa extensão média das encostas em torno dos $35 \mathrm{~km}$ indica uma relação positiva para o deslocamento rápido de águas de superfície em direção ao canal do rio Verde.

Seguindo pelo ribeirão da Mutuca em direção ao rio Sucuriú no perímetro norte do Município, e deste ate chegar ao rio Paraíso os terrenos apresentam valores altimetricos variando dos 400 metros ate aproximadamente 750 metros.

Comparando-se ao espaço anterior as encostas são menos extensas e as crenulações das curvas de nível indicam ser esse o espaço de maior adensamento de fundos de vales definindo ser área onde o fluxo de águas superficiais, apresente menor extensão de percurso e consequentemente maior velocidade de deslocamento.

Seguindo a linha perimental leste sudeste definido pelo canal fluvial do rio Sucuriú e deste em direção ao divisor de águas com a bacia do rio São Domingos a topografia mostra uma variação altitudinal desde o canal do rio Sucuriú em torno dos 350 metros ate o divisor topográficos daqueles canais em torno dos 770 metros, definindo uma amplitude altimétrica de 420 metros. Nestas encostas de vertentes a probabilidade do adensamento da rede hidrográfica indicada nas crenulações das curvas mostra de médico abaixo adensamento, porem as superfícies de topografias tabulares escarpadas indicam potencialidades futuras para o surgimento de novos cursos d' água. Pensar assim exige valorizar a estreita largura tanto do canal do Rio Sucuriú como no canal do rio São 
Domingos, indicadores do aumento do desnível nas encostas e então do aparecimento de novos cursos de águas.

\section{CONCLUSÃO}

O Estado de Mato Grosso do Sul, quando da divisão em 1977 tinha 55 Municípios. Em 2012 já possuía 78 novos Municípios e no inicio de 2013 ganhou mais um, Paraíso das Águas. Apesar de possuir 24 novos Municípios, a distância entre eles tem sido altamente prejudicial à realização de investimentos individuais na busca da redução dos problemas originados pela produção do lixo, principalmente domésticos.

A modernização tem incluído a necessidade da construção de aterros sanitários, usinas de processamentos do lixo e a legalização da profissão de catadores, tudo isso porque a educação do ser humano brasileiro e sul mato-grossense está habituada a se desfazer e não em contribuir para o reaproveitar.

O lixo é responsável por uns dos mais graves problemas ambientais que a humanidade tem criado e enfrentado nos últimos tempos, devido ao intenso consumo de embalagens e produtos descartáveis que ocorre na sociedade. Outro fator bastante preocupante é com a disposição final desses resíduos, pois a maioria do lixo não recebe tratamento adequado gerando assim doenças transmitidas pelos vetores.

Seu volume vem aumentando não só nos grandes centros urbanos, mas também nos pequenos municípios como observamos no mais novo município o Mato Grosso do Sul, Paraíso das Águas, sendo depositado em grande terreno a céu aberto popularmente conhecido como lixão, gerando assim mais um problema ambiental, tendo em vista a poluição do lençol freático devido à presença do chorume, tendo ainda o agravante da proximidade de cursos d'água representativos no contexto hidrográfico estadual.

Ultimamente, com a preocupação gerada pelo lixo depositado a céu aberto, o Município tem estado transferindo representativo volume para área no município vizinho (Chapadão do Sul). Isto, por si só desperta a necessidade de se encontrar alternativa para solucionar o problema do lixo, como por exemplo, o da implantação de uma Unidade de Processamento de Lixo - UPL, envolvendo o trato final do material reciclado a ser transformado; o lixo orgânico, dando-lhe o destino final da compostagem; e o aterro sanitário para outros tipos de lixo, conforme definido na Lei de Resíduos Sólidos, ou seja, 
dar-se-ia o destino certo para cada tipo de resíduo: Domiciliar, Comercial, Público, Serviços de saúde, Industrial, Agrícola e Entulho. Atrelado à construção da Usina de Processamento, a separação e a coleta seletiva, dentro das prioridades previstas durante a conferência do meio ambiente (resíduos sólidos) ocorrida em julho de 2013, se somariam como indicadores ideais na busca não somente da conscientização ambiental e geração de renda, como também na reutilização do material reciclado e transformado, que podem gerar rendas e economia para as empresas e redução de desperdícios, diminuiria a poluição dos solos e rios.

Outro agravante são os custos intermediários entre a comercialização dos serviços praticados na UPL e as indústrias transformadoras compradoras, principalmente porque no estado de Mato Grosso do Sul o distanciamento entre as sedes urbanas dos municípios tem sido um fator que ao invés de ser o problema, poderia ser a solução com a instalação destas indústrias no Estado, distribuídas espacialmente para atender grupamentos de municípios.

Considerados ainda as condições ambientais ideais para a instalação de UPL, no caso do município de Paraíso das Águas, há que se levar em conta o substrato geológico bem como o adensamento das redes de drenagem fluviais e extensão das encostas do relevo, como itens fundamentais em sua localização. No exame desses itens, considerouse a região Oeste, dentro da área do município, em terras da bacia do rio São Domingos, onde a estrutura física de uma UPL possa vir a ser instalada, pensando-se é claro, em riscos futuros ao ambiente físico, ou seja, rochas de ambiente eólico, de médio a baixo adensamento da rede de drenagem e, maior extensão das encostas.

\section{REFERÊNCIAS}

BRASIL. Secretaria de Planejamento da Presidência da Republica. Cabeceira do Aporé, IBGE- Diretoria de Geodésia e Cartografia.1976. FOLHA SE-22-Y- A-VI. Carta Planialtimétrica, color, 73×60 cm. Escala 1:100 000 (Primeira Edição).

Secretaria de Planejamento da Presidência da Republica. Ribeirão Boa Vista, IBGE- Diretoria de Geodésia e Cartografia. 1982. FOLHA SE.22-Y-C-VI - MI-2517. Carta Planialtimétrica, color, 73×60 cm. Escala 1:100 000 (Segunda Edição)-1982. 
.Diretoria de Serviço Geográfico. Costa Rica, 1997. FOLHA SE-22-YAV. Carta Planialtimétrica, color, $73 \times 60 \mathrm{~cm}$. Escala 1:100 000 (Terceira impresão).

Secretaria de Planejamento da Presidência da Republica. Rio São Domingos, IBGE- Diretoria de Geodésia e Cartografia.1978. FOLHA SE-22-Y-C-V. Carta Planialtimétrica, color, $73 \times 60 \mathrm{~cm}$. Escala 1:100 000 (Primeira Edição).

Secretaria de Planejamento da Presidência da Republica. Alto Sucuriú, IBGEDiretoria de Geodésia e Cartografia, 1976. FOLHA SE-22-Y-C-III. Carta Planialtimétrica, Color, $73 \times 60 \mathrm{~cm}$. Escala 1:100 000 (Primeira Edição).

Secretaria de Planejamento da Presidência da Republica. Ribeirão Brejão, IBGE- Diretoria de Geodésia e Cartografia,1978. Carta Planialtimétrica, FOLHA SE-22-YC-I, color, 73×60 cm. Escala 1:100 000 (Primeira Edição).

- Secretaria de Planejamento da Presidência da Republica. . Paraíso, IBGEDiretoria de Geodésia e Cartografia, 1976. Carta Planialtimétrica, FOLHA SE-22-Y-C-II, color, 73×60 cm. Escala 1:100 000 (Primeira Edição).

. M.M.E/D.N.P.M. Mapa Geológico do Estado do Estado de Mato Grosso do Sul, Edição Digital. Campo-Grande-MS, 2006. Color, escala 1:100 000.

MATO GROSSO DO SUL, Guia Pedagógico de Resíduos Sólidos. Prefeitura Municipal de Campo-Grande, 2012, 94 p.

LEÃO, A.L. Manejo de Resíduos Sólidos Urbanos Para Produção de Energia e Novos Materiais. In: Tauk-Tornisielo et al, org. Análise Ambiental Estratégias e Ações T.A Queiroz,São Paulo: Editor, LTDA, 1995.Cap.6, 238:243.

MATO GROSSO DO SUL, SEMAC/MS. Dados Estatísticos dos Municípios de MS. Paraíso das Águas, 2013. Disponível em: <www1.semac.ms.gov.br/bdeweb/> Acesso em Jul 2013.

PARAÍSO DAS ÁGUAS. Primeira Conferência Municipal do Meio Ambiente, 2013. Disponível em:< www.imasul.ms.gov.br/controle/ShowFile.php?id=139767> Acesso em Ago 2013. 